\title{
Sandiwara Sunda sebagai Bentuk Transmisi Nilai bagi Generasi Muda
}

\author{
Retno Dwimarwati dan Afri Wita \\ Sekolah Tinggi Seni Indonesia (STSI) Bandung \\ Jl. Buah Batu No. 212 Bandung 40265
}

\begin{abstract}
Character education is nowadays being promoted in national education system since it is considered to be able to enhance the character of present and future generation. Character building cannot be separated from culture. In this case, Ringkang Gumiwang Arts House (RGAH) concerns on character education by reintroducing mother language (Sundanese) as an effort to build one's culture. Reconstructing Sundanese play is conducted as an attempt of retaining the existence of Sundanese culture. The performance of Sundanese play grows into media of maintaining language and arts for young generation. Arts inheritance method is implemented to explore and apply the sustainment of arts in the society. Understanding of values in the performance is expected to be applied in the youth life. Therefore, the performance appreciation run by RGAH can be a model in transmitting values of a society. Plays (Sandiwara) become a good vehicle to increase appreciation among the youth.
\end{abstract}

Keywords: Sundanese plays, values transmission, young generation

\begin{abstract}
ABSTRAK
Pendidikan karakter kini tengah digalakkan dalam sistem pendidikan nasional karena dapat meningkatkan mutu karakter generasi sekarang dan masa datang. Kita tidak mungkin membangun karakter terlepas dari budayanya. Padepokan Seni Ringkang Gumiwang (PSRG) peduli pada pendidikan karakter dengan mengenalkan kembali bahasa ibu(Sunda) sebagai upaya membangun budaya sendiri. Rekonstruksi Sandiwara Sunda dilakukan sebagai upaya pemertahanan eksistensi budaya Sunda. Pertunjukan sandiwara Sunda menjadi media pemertahanan bahasa dan seni kepada generasi muda. Metode Pewarisan kesenian digunakan untuk menggali dan mengaplikasikan keberlangsungan sebuah kesenian di masyarakat. Pemahaman nilai-nilai yang terkandung di dalam pertunjukan diharapkan dapat diaplikasi dalam kehidupan siswa (generasi muda). Oleh karena itu, apresiasi pertunjukan yang dilakukan oleh PSRG dapat menjadi model dalam transmisi nilai pada masyarakat. Sandiwara menjadi wahana tepat dalam peningkatan apresiasidi kalangan generasi muda.
\end{abstract}

Kata kunci: Sandiwara Sunda, transmisi nilai, generasi muda

\section{PENDAHULUAN}

Pertumbuhan dan perkembangan Sandiwara Sunda di Jawa Barat, terutama di kota besar seperti Bandung, Sumedang, Garut, Tasik, Bogor, Sukabumi, dan Cianjur pada sekitar tahun 1960 merupakan tempat-tempat yang memiliki kelompok sandiwara yang cukup terkenal dan sering mengadakan pertunjukan. Hampir di setiap pasar, terutama di Bandung,memiliki gedung pertunjukan sandiwara, seperti pasar Kosambi (Kelompok Sri Murni), pasar 
Remas Condong, Dayeuh Kolot (kelompok Sinar Budaya), Pasar Banjaran (kelompok Sinar Mustika), Tegalega (kelompok Sinar Muda), dan daerah Sukajadi (kelompok Purwa Setra). Selain itu ada beberapa kelompok sandiwara gembol yang melakukan pementasan secara berkeliling, seperti Sanggar Victa dan Jati Nugraha. Adapun kelompok Sri Murni di Pasar Kosambi tergusur karena perombakan pasar, terpecah menjadi tiga kelompok, yaitu Sri Murni, Sri Mukti, dan Dewi Murni yang kemudian berpentas di Gedung Kesenian Rumentang Siang (GKRS) Bandung.

Keberlangsungan pementasan Sandiwara Sunda diwadahi oleh GKRS Bandung berlangsung sejak tahun 1975 hingga 1990-an, namun lambat laun frekuensi pertunjukan mereka semakin tidak menentu sehingga penonton pun semakin hilang dan akhirnya mereka tidak pernah melakukan pertunjukan sama sekali. Pertunjukan Sandiwara Sunda hampir musnah meskipun kelompok-kelompok tersebut masih ada, namun mereka tidak pernah lagi melakukan pementasan.

Sandiwara Sunda dapat mewakili berbagai bentuk kesenian Sunda karena memiliki unsur tari, nyanyi, musik, lawakan, dialog, dan akting dalam bentuk roman, babad, wayang, dan Desick, maka bentuk ini dapat mewadahi keseluruhan bentuk kesenian Sunda. Bentuk pertunjukan yang sarat unsur tersebut jika punah akan hilang pula berbagai bentuk seni tradisi yang dimiliki budaya Sunda. Oleh karena itu, diperlukan upaya penggalian kembali bentuk dan nilai-nilai yang pernah diminati oleh masyarakat pada waktu itu. Dengan mengenal bentuk seni tradisi Sunda diharapkan generasi muda lebih mengenal jati diri dan menghargai nilai-nilai budaya sendiri. Brandon mengatakan sebuah pertunjukan akan bertahan jika mendapatkan 'kontrak sosial' dalam mengatur kelompok tersebut dengan pendukungnya. Dukungan terse- but berupa keterikatan dengan pemerintah, dukungan ekonomi, dan dukungan komunal (Endang Caturwati, 2011: 40).

Sebuah kelompok pertunjukan dapat bertahan jika frekuensi pertunjukan berjalan dengan baik, terjadi proses pewarisan/ regenerasi, dan tersedianya publik yang menonton pertunjukan tersebut. Jika hal ini dilakukan secara terus nenerus maka keberlangsungan sebuah kelompok akan dapat dipertahankan. Sandiwara Sunda sejak awal pertumbuhannya merupakan seni populer yang berorientasi pada keuntungan (profit oriented) dan menjadi konsumsi kaum urban di berbagai kota di Jawa Barat (Sunda). Sebuah bentuk seni komersial yang menghibur penontonnya dengan tema-tema yang aktual pada saat itu. Dengan perubahan kondisi masyarakat dan zaman para awak sandiwara tak mampu mengikuti keinginan penonton sehingga lambat laun semakin ditinggalkan penontonnya. Oleh karena itu, pertunjukan hiburan berbahasa Sunda yang sarat dengan unsur seni Sunda memerlukan penanganan khusus untuk bangkit kembali sehingga generasi muda mengenal seni budaya sebagai warisan yang berharga.

Berdasarkan fenomena tersebut, dipilih satu kelompok dari mereka sebagai sumber acuan ketangguhan dalam membangkitkan kembali Sandiwara Sunda melalui kiprah Padepokan Seni Ringkang Gumiwang (PSRG) pimpinan E. Samsudin yang lebih dikenal dengan nama Wa Kabul. PSRG mencoba bangkit kembali dengan melakukan terobosan dalam menjaring penonton. Mereka melakukan kerja sama dengan sekolah-sekolah dalam program apresiasi pertunjukan. Satu judul pementasan dapat dilakukan berkali-kali selama setahununtuk konsumsi sekolah-sekolah yang berbedadi beberapa gedung pertunjukan yang ada di kota Bandung, seperti GKRS, Sunan Ambu (STSI) Bandung, dan Taman Budaya Provinsi Jawa Barat. Dengan 
demikian, Sandiwara Sunda dapat menjadi media pembelajaran pada generasi muda, baik dalam apresiasimaupun praktik pertunjukan seni.

Kebangkitan kelompok Ringkang Gumiwang menjadi pemicu yang menarik untuk melakukan penelitian pada Sandiwara Sunda yang nyaris punah.Hal tersebut dilakukan agar dapat menggali kembali pertunjukan sandiwara yang sebenarnya atau mencari model baru berdasarkan acuan teater sebagai konsumsi publik yang mendidik dan menarik. Penggalian tentang bentuk pertunjukan diharapkan dapat menemukan model sandiwara yang dapat disesuaikan dengan kebutuhan masyarakat saat ini, terutama generasi muda. Bagaimana pelatihan dan pengemasan Sandiwara Sunda agar menjadi pertunjukan yang diminati dengan kualitas pertunjukan yang juga memadai bagi generasi muda? Bagaimana pula cara melakukan sosialisasi hasil rekonstruksi bentuk pertunjukan tersebut.

\section{PEMBAHASAN}

\section{Padepokan Seni Ringkang Gumiwang dan Pemertahanan Sandiwara Sunda}

Kelangsungan kelompok seni pertunjukan tidak terlepas dari tiga unsur yang melingkupinya,yaitu pertunjukan, pelaku, dan penonton. Apabila salah satu dari tiga unsur tersebut tidak hadir maka tidak dapat dikatakan sebagai pertunjukan. Sebuah kelompok pertunjukan dapat bertahan jika frekuensi pertunjukan berjalan dengan baik, terjadi proses pewarisan/regenerasi, dan tersedianya publik yang menonton pertunjukan tersebut. Oleh karena itu, proses pemertahanan ketiga unsur tersebut harus terus menerus diupayakan. Sandiwara Sunda sebagai sebuah bentuk pertunjukan yang kini menjadi non profit

harus memiliki kiat khusus dalam penanganannya. Apabila Miss Tjitjih di Jakarta mendapat subsidi dari pemerintah Daerah Khusus Ibu Kota (DKI) Jakarta, Sandiwara di Jawa Barat yang menjadi tanah kelahirannya harus berupaya sendiri untuk bangkit kembali. Seperti yang dikatakan Permana dalam Harian Umum Pikiran Rakyat (7 Maret 2010),

"Sandiwara Sunda, bahkan di kam-
pung halamannya sendiri, di Priangan,
hancur sudah. Mungkin belum han-
cur jadi debu, sebab di Bandung, grup
sandiwara Sunda sudah puluhan tahun
tak punya gedung dan tak memiliki pe-
minat. Mereka hanya manggung ber-
giliran dua minggu sekali di Gedung
Kesenian Rumentang Siang, itu pun ti-
dak konsisten. Lain halnya dengan ke-
lompok Sandiwara Sunda 'Miss Tjitjih'
di Jakarta yang telah memiliki gedung
sendiri yang representatif dan dipeli-
hara oleh Pemda DKI, namun subsidi
ini pun tetap tak mampu menjaring
penonton. Hal ini disebabkan orang
Sunda tersebar dan kesulitan menjang-
kau tempat pertunjukan juga karena
tergerusnya rasa cinta orang Sunda ter-
hadap lakon-lakon Sunda."

Miss Tjitjih menjadi model pewarisan dan pelestarian budaya Sunda yang disubsidi oleh pemerintah, sehingga dua dukungan pemerintah dan ekonomi seperti yang disebutkan oleh Brandon dapat terpenuhi. Akan tetapi ketika dukungan komunal tidak terpelihara maka kelangsungan pertunjukan tidak seimbang karena sedikit penontonnya. Oleh karena itu PSRG melakukan upaya menjaring penonton meskipun tidak memiliki dukungan pemerintah. Jika penonton terbina maka secara ekonomi hal ini akan membantu kelangsungan hidup kelompok tersebut.

Lingkung Seni Jati Nugraha adalah nama awal sebelum menjadi Padepokan Seni Ringkang Gumiwang. Kelompok ini sudah mulai meraih pendukung dari kelompok kaum muda, termasuk di dalamnya mahasiswa. Mereka mulai memikir- 
kan sistem organisasi dengan memiliki staf organisasi, Anggaran Dasar (AD) dan Anggaran Rumah Tangga (ART), program jangka panjang dan jangka pendek (Yuyu Wahyudin, 1986: 3). Kelompok ini pernah menyerap penonton sebanyak 203 orang dalam pementasan 'Kapahung' tahun 1986. Hal ini terjadi karena upaya Lingkung Seni dengan cara-cara yang lebih modern, seperti adanya planning, organizing, actuating, controlling, baik untuk persiapan latihan, pementasan, dan peraihan penonton. Upaya untuk menarik penonton dilakukan dengan publikasi melalui pamflet, poster, radio, surat kabar, dan sponsor (Wahyudin, 1986: 29).

Upaya yang dilakukan oleh PSRG untuk menghadapi zaman baru adalah dengan cara: Unsur penting dalam pertunjukan, yaitu bentuk pertunjukan, pemain, dan penonton menjadi acuan untuk melihat kinerja PSRG dalam merekonstruksi Sandiwara Sunda.

\section{Bentuk Pertunjukan}

Pertunjukan Sandiwara Sunda yang dilakukan oleh PSRG memiliki perbedaan kemasan dengan pertunjukan asli karena alasan pembinaan. Pertunjukan yang biasa dilakukan dengan lima babak dalam sandiwara sebenarnya dijadikan dua babak ditambah dengan satu selingan babak tambahan. Hal ini dilakukan dengan menggabungkan Babak satu dan dua dalam pertunjukan aslinya. Babak satu sebagai eksposisi, seperti 'turunnya perintah' atau 'keinginan mencapai sesuatu', dimasukkan dalam perjalanan di Babak dua sehingga esensi permasalahan yang ada di Babak satu tetap terungkap meskipun hanya melalui dialog pemeran.

Fungsi didaktik menjadi prioritas dalam pertunjukan sandiwara PSRG. PSRG menganggap bahwa ketakberpihakan ma- syarakat pada kebudayaan Sunda perlu diantisipasi agar generasi muda kenal dan cinta pada budayanya sendiri. Oleh karena itu, bentuk Sandiwara dihadirkan dalam bentuk kemasan menarik memenuhi fungsi didaktik dan rekreatif. Bentuk pertunjukan sandiwara yang terdiri dari nyanyian, tarian, dialog, lawakan, akrobat, dan cerita tetap dipertahankan meskipun porsinya jauh lebih sedikit dibandingkan dengan pertunjukan aslinya.

Hal yang menarik dalam pertunjukan sandiwara adalah adanya tokoh favorit yang dapat menjadi nilai jual sebuah kelompok. Penonton akan tertarik pada tokoh primadona dan pelawak (bodor). Primadona memiliki nilai jual tersendiri dalam pertunjukan sandiwara. Hal ini diungkapkan oleh Abdulkadir \& Rosyid, di mana "Sandiwara dari zaman lampau memakai sistem prima donna atau seri panggung. Kechekapan dan Kechantekan seri panggong ini lah menjadi central point atau daya penarek perdagangan sesuatu rombongan Indera Bangsawan" (1961: 147). Primadona dan pelawak (bodor) ini lah yang selalu diminati masyarakat sehingga ketika nama tersebut dipampang dalam baligo besar atau disiarkan melalui pengumuman keliling akan menarik minat penonton datang ke tempat pertunjukan. PSRG tidak memiliki primadona yang terkenal seperti zaman keemasan sandiwara di mana penonton datang karena kemashuran, kecantikan, dan kepiawaian aktor tersebut. Upaya yang dilakukan oleh kelompok ini adalah mengundang bintang tamu yang cukup dikenal untuk menarik minat penonton dan lebih dekat pada aktor bodor daripada mencari primadona yang kini hampir tidak ada.

Sandiwara Sunda memiliki empat jenis cerita, yaitu: Roman, Babad, Wayang, dan Desick. Roman mengisahkan tentang kehidupan sehari-hari rakyat biasa dengan persoalan cinta, rumah tangga, pergaulan 
masyarakat, dan hal-hal aktual di masyarakat; Babad mengisahkan tentang sejarah kerajaan, hikayat pahlawan yang terkenal di masyarakat, atau legenda yang hidup di suatu daerah tertentu; Wayang mengambil cerita dari Ramayana dan Mahabharata yang sangat terkenal di masyarakat; sedangkan Desick berkisah tentang cerita 1001 malam dari Parsi, Bagdad, dan Timur Tengah. Hal ini memungkinkan untuk elaborasi cerita yang lebih luas dari PSRG. Setiap pertunjukan dapat mencari sumber cerita yang dapat disesuaikan dengan kebutuhan penontonnya.

\section{Pelaku/pemain}

Aktor Sandiwara Sunda pada masa kejayaannya adalah pemain profesional. Mereka memiliki peran-peran khusus dengan karakter tertentu (type casting). Permainan aktor dalam Sandiwara Sunda lebih bersifat improvisasi sehingga pemimpin kelompok hanya memberikan garis besar cerita yang akan dimainkan kemudian dikembangkan oleh para pemain secara improvisasi. Mereka mendapatkan arahan permainan setelah siap dengan kostum dan make up. Dengan mengetahui judul yang akan mereka mainkan, mereka langsung memahaami peran dan posisi masing-masing dalam pertunjukan tersebut. Sebagai pemain profesional mereka hafal betul dengan berbagai dialog, situasi-situasi tertentu, dan dalam menghadapi tokoh lain sebagai lawan mainnya.

Hal tersebut sangat berbeda dengan pemain Sandiwara Sunda sekarang, yang tidak memiliki ketrampilan khusus sehingga proses latihan perlu dilakukan dengan menggunakan naskah sebagai acuan. Selain mempelajari kesenian dalam pertunjukan Sandiwara Sunda, pemain pun dapat membekali diri dengan kemampuan berbahasa Sunda yang kini mulai ditinggalkan oleh generasi muda. Proses berkesenian di- dapat melalui pelatihan akting bagi pemain (aktor), musik, tari, maupun hal-hal teknis bagi crew yang sangat diperlukan dalam pertunjukan Sandiwara Sunda.

Proses ini menjadi berharga karena dengan adanya naskah maka para pemain dapat mempelajari kosa kata bahasa Sunda, merasakannya, dan mendapatkan praktik langsung dalam berbahasa, juga tersedianya sumber cerita yang dapat didokumentasikan. Sumber cerita seni tradisi lebih banyak dengan cara lisan sehingga dari generasi ke generasi cerita dapat berubah dan dapat semakin menghilang. Apabila ini dikerjakan dengan tekun maka akan dihasilkan ketrampilan dan kecintaan yang mendalam pada Seni Sunda.

Cara-cara di atas berbeda dalam pewarisan tradisional yang memerlukan proses panjang dalam sistem pewarisan kesenian, baik melalui cara turunan, katurunan, dan tuturunan. Melalui proses tersebut seseorang akan menjadi seniman dengan ketertarikan dan upaya yang sangat gigih, tekun, dan serius dalam mengikuti perjalanan sebuah kelompok berdasarkan panggilan jiwanya sehingga aktivitas kelompok tersebut menjadi bagian dari dirinya. Hasil proses ini terinternalisasi dalam diri pemain Sandiwara Sunda sehingga mereka menjadi pemain profesional.

\section{Penonton}

Penonton adalah unsur penting yang dapat menghidupkan sebuah pertunjukan dan kelompok kesenian. Hal ini sesuai dengan yang dikemukakan Cameron dan Gillespie, "An audience is a group drawn together by a theatrical event at a certain time and place. That is aware pf it self as a group"(1980: 28). Penonton Sandiwara Sunda pada masa awal adalah masyarakat yang hidup mengembara dan mencari penghidupan di kota-kota yang baru tumbuh pada saat itu. Kalangan 
masyarakat baru ini tergolong pada kelas menengah ke bawah yang membutuhkan hiburan sesuai dengan selera dan keuangan mereka. Tobong Sandiwara Sunda menjadi alternatif tontonan yang dapat memenuhi kebutuhan mereka. Akan tetapi, keakraban yang biasa terjalin antara penonton dengan Tobong dari setiap kelompok Sandiwara Sunda menjadi hilang ketika mereka mulai bermain di gedung pertunjukan.

Penonton kemudian beralih pada kaum terpelajar sehingga hal ini menjadi masalah baru yang mengharuskan Sandiwara Sunda mencari formula baru dalam memenuhi selera penonton yang berbeda jika ingin kelompoknya terus berlangsung. Penonton terpelajar membutuhkan hal yang aktual dan progresif dalam menikmati pertunjukan, sedangkan pemain sandiwara yang kebanyakan tidak berpendidikan/otodidak tidak dapat memenuhi kebutuhan kaum terpelajar. Oleh karena itu, bila kini PSRG akan meraih kelompok terpelajar dalam menghidupkan lagi Sandiwara Sunda maka kelompok ini juga harus meraih pemain dari generasi muda.

\section{Transmisi Nilai}

Proses transmisibudayabiasa dilakukan dalam proses pendidikan. Dalam tulisan ini transmisi dimaksudkan untuk mengajarkan karakter pada generasi muda. Karakter mendemonstrasikan etika atau sistem nilai personal yang ideal (baik dan penting) untuk eksistensi diri dan berhubungan dengan orang lain. Pengertian karakter dalam kamus adalah: ... "the combination of qualities or features that distinguishes one person, group, or thing from another" (American Heritage Dictionary of the English Language: 4th edition).

Pendidikan karakter dapat dimaknai sebagai pendidikan nilai, pendidikan budi pekerti, pendidikan moral, pendidikan watak, yang bertujuan mengembangkan kemampuan peserta didik untuk memberikan keputusan baik-buruk, memelihara apa yang baik, mewujudkan dan menebar kebaikan itu dalam kehidupan sehari-hari dengan sepenuh hati.

Dengan demikian apa yang menjadi visi PSRG dengan menampilkan sebuah pertunjukan dapat mengajarkan beberapa nilai sebagai sebuah satu kesatuan konsep. Nilai-nilai yang didapat dari bentuk pertunjukan menghasilkan nilai estetika, konsep target siswa sebagai penontonnya menghasilkan nilai ekonomi dan pendidikan budi pekerti (etika). Hal tersebut sangat tergantung pada konsep bingkai pertunjukan yang dipilih PSRG. Konsep framework yang dipilih dapat meningkatkan kinerja sebuah kelompok kesenian dengan memperhatikan bentuk seni, sektor pasar, dan kompleksitas proses setiap unsurnya. McCarthy menyatakan bahwa, using this conceptual framework, we are able to compare arts activities within art form, market sector, and fuctional domains over time, and consider how activities across the various dimensions may be related (2001: 9). Framework ini secara praktik dilakukan oleh PSRG dengan memperhatikan bentuk pertunjukannya, pangsa pasar, dan kesatuan berbagai ranah fungsional yang saling terkait. Upaya yang dilakukan PSRG sebagai bentuk kelompok seni pertunjukan adalah melakukan berbagai strategi untuk menghidupi kelompoknya, yaitu dengan cara: bentuk pertunjukan yang dipilih adalah Sandiwara Sunda. Hal ini sangat tergantung pula bagaimana pangsa pasar yang ditargetkan. Ketika PSRG memilih Sandiwara Sunda sebagai bentuk pilihannya dan target sekolah menengah sebagai pangsa pasarnya, maka pimpinan PSRG memadatkan pertunjukan dari lima babak menjadi dua babak dengan satu selingan. Hal ini dilakukan karena dalam Sandiwara Sunda asli setiap pergantian babak selalu dimainkan satu lagu penuh termasuk permintaan penonton. Se- 
bagai akibatnya pertunjukan berjalan panjang dan ini memerlukan kekuatan dalam mengapresiasi, terutama bagi penonton pemula.

Kemasan pertunjukan pun betul-betul harus diperhitungkan dengan bentuk yang lebih menghibur, adegan-adegan formal dan sangat monoton seperti adegan kerajaan yang penuh dengan permainan katakata tingkat tinggi dihilangkan, karena akan terasa membosankan bagi penonton yang tidak akrab dengan bahasa Sunda halus tingkat tinggi. Adegan dipilih langsung pada adegan perjalanan antara pangeran atau ksatria atau pemuda yang mendapat tugas dari kerajaan/pertapaan ditemani dengan punakawan, lengser, atau pembantu (badega) yang biasanya muncul dengan karakter lucu. Dalam kaitan ini meskipun adegannya serius tetapi penuh dengan humor berisi konflik antar bawahan. Kehadiran tokoh ini ada di setiap adegan sehingga kelucuan selalu hadir dan membuat pertunjukan menjadi menarik.

Pertunjukan yang berulang-ulang memungkinkan untuk memperpendek program latihan karena pemain sudah disiapkan dengan peran yang sering dimainkannya. Pemanggilan aktor atau artis yang dikenal pun dilakukan untuk menarik minat penonton dalam adegan selingan tertentu. Artis tersebut tidak memainkan dirinya sendiri tetapi memainkan tokoh yang disesuaikan dengan kebutuhan cerita.

Sektor Pasar diperhitungkan dengan menetapkannya sebagai bentuk teater populer yang berorientasi pada penonton sehingga perhitungan target pelajar menjadi sangat kuat. Mereka mencoba melakukan strategi dengan menurunkan biaya produksi dan meningkatkan apresiator dalam setiap pertunjukannya. Satu naskah dimainkan berulang-ulang sehingga frekuensi pertunjukan sangat padat. Apabila satu hari berlangsung tiga sampai empat kali pertunjukan dengan penonton tigaratus orang, maka satu hari dapat dikumpulkan sekitar seribu penonton. Bila tigapuluh sekolah dihubungi dalam satu event pertunjukan, maka dapat kelompok ini dapat mengumpulkan 10.000 penonton dalam satu naskah. Hal tersebut telah dilakukan oleh PSRG.

Jalinan kerja sama tetap dilakukan oleh pihak manajemen PSRG dengan sekolahsekolah yang telah menjadi kelompok PSRG sehingga dalam pertunjukan atau produksi yang lain mereka dapat dihubungi dan sekolah mereka dapat menjadi apresiator yang tetap. Siswa SMP maupun SMA senantiasa berganti sehingga setiap sesi pertunjukan pun dapat mengganti apresiator yang dibutuhkan. Hal ini dapat membuat prediksi berapa penonton yang akan hadir, bila jumlah sekolah dan muridnya sebagai apresiator setiap tahun telah ditentukan. Penonton melakukan pemesanan tempat (booking) terlebih dahulu sehingga jadwaljadwal yang dilakukan oleh PSRG ini pun harus menyesuaikan dengan gedung pertunjukan. GK Rumentang Siang yang biasa menjadi tempat pertunjukan mereka senantiasa terlihat padat. Oleh karena itu, kadang rentetan pertunjukan mereka harus berselang dahulu dengan pertunjukan lainnya.

\section{PENUTUP}

Padepokan Seni Ringkang Gumiwang merupakan kelompok Sandiwara Sunda satu-satunya di Jawa Barat yang masih bertahan melakukan pertunjukan. Kelompok ini melakukan pembaharuan dan penyesuaian bentuk pertunjukan sesuai dengan target pasar yang dipilihnya. Penyesuaian tersebut dilakukan baik terhadap bentuk pertunjukan, pelaku, maupun penontonnya. Cerita yang dilakukan oleh PSRG sudah memakai pendekatan teater modern, penulis naskah sebagai ketua rombongan 
dan sutradara paham betul tentang kondisi dan kebutuhan para pemainnya. Cerita ditulis secara lengkap dengan pertunjukan dua babak ditambah dengan selingan sehingga berdurasi sekitar sembilan puluh menit dengan dialog ringan dan menghibur.

Kelompok ini melakukan pengemasan Sandiwara Sunda dengan pertunjukan yang menarik disesuaikan dengan target pasar yang sudah ditentukan. Bentuk ini lah yang terus dikembangkan oleh Kabul E. Samsudin dalam menghidupkan PSRG dengan pertunjukan yang ringan dan menghibur. Kini PSRG yakin bahwa penonton yang menjadi pangsa pasarnya adalah kaum terpelajar. Kelompok ini mencoba mengenalkan bentuk pertunjukan khas Sunda (Jawa Barat) yang kini hampir punah pada generasi muda di samping memberikan didaktik tentang budi pekerti yang sudah tidak diajarkan di kurikulum sekolah. Sandiwara Sunda selain mengajarkan bentuk pertunjukan, dan budaya Sunda di dalamnya berisi tentang tari, musik, lawakan, dan terutama bahasa Sunda.

Pengemasan Sandiwara Sunda menjadi pertunjukan yang diminati dengan kualitas pertunjukan yang juga memadai bagi generasi muda dilakukan dengan cara memperhatikan aspek yang menjadi ciri sandiwara. Dalam kaitan ini aspek pertunjukan tidak dihilangkan namun dipadatkan dengan mengisi humor dan kelucuan serta menampilkan celotehan para panakawan dan abdi tokoh utama.

Sosialisasi sandiwara Sunda dilakukan dengan mengumpulkan guru dan Dinas Pendidikan (Disdik) untuk menonton pertunjukan perdana mereka, kemudian dilakukan diskusi untuk memperoleh umpan balik atas pertunjukannya. Apabila guruguru menganggap bahwa pertunjukan tersebut layak diapresiasi oleh siswanya, maka mereka kemudian melakukan tin- dak lanjut dengan pemesanan tiket untuk program apresiasi di sekolah-sekolah. Oleh karena orientasi pasar PSRG adalah pelajar, maka pertunjukan yang dibuat senantiasa mengacu pada persoalan didaktik terutama budi pekerti yang kini mulai digalakan lagi oleh pemerintah. Pengenalan jati diri bangsa dilakukan dengan manifestasi kecintaannya terhadap bahasa, kesenian, serta budaya secara keseluruhan. Program ini dibuat dengan visi mengajarkan budi pekerti dengan cara yang menyenangkan. Sehingga apabila program ini dilaksanakan secara berkelanjutan maka pendidikan berbasis budaya yang menanamkan berbagai nilai kehidupan dapat menjadi model yang menarik minat generasi muda.

\section{Daftar Pustaka}

Abdulkadir, Teungku Syed \& Rosdy, Zen. 1961 Sejarah Seni Drama. Singapura: Malaysia Press Ltd.

Anwari

1999 Indonesia Tertawa, Srimulat sebagai Sebuah Subkultur. Jakarta: Pustaka LP3ES Indonesia.

Arif Merdeka Permana

2010 "Miss Tjitjih dan Sandiwara Sunda" dalam Harian Umum Pikiran Rakyat, Rubrik Khazanah, hal. 16. 7 Maret 2010.

Cameron, Kenneth M. \& PattiP. Gillespie 1980 The enjoyment theatre. New York: McMillan Publishing Company.

Cohen, Issac Matthew

2006 The Komedie Stamboel: Popular Theater in Colonial Indonesia, 1891-1903. Ohio: Ohio University Press. 
Endang Caturwati

2011 Sinden-Penari di Atas dan di Luar Panggung. Bandung: Pustaka Pelajar dan Sunan Ambu Press.

McCarthy, Kevin.,et.al.

2001 The Performing Arts in a New Era.

Pittsburg: RAND
Yuyu Wahyudin

1986 Tinjauan Deskriptif Proses Produksi Pementasan Sandiwara Sunda Lingkung Seni Jati Nugraha. Bandung: Akademi Seni Tari Indonesia (ASTI). 